\title{
Penguatan Konsep Filosofi Perebutan Tirta Amertha pada Taman di Jalan Ngurah Rai Kecamatan Gianyar, Kabupaten Gianyar, Provinsi Bali
}

\section{ANAK AGUNG ISTRI MIRAH FEBRIYANI ${ }^{1}$, NI WAYAN FEBRIANA UTAMI ${ }^{*}$, COKORDA GEDE ALIT SEMARAJAYA ${ }^{1}$}

1. Program Studi Arsitektur Pertamanan, Fakultas Pertanian, Universitas Udayana Jl. PB. Sudirman, Denpasar, 80114, Indonesia

*E-mail: wayan_febriana@unud.ac.id

\section{ABSTRACT \\ Robustness of the Concept of Tirtha Amertha Philosophy on Park of Ngurah Rai street in Gianyar Subdistrict, Gianyar Regency, Bali Province}

City Park is a park that situated in urban environment. In a wide scale it can anticipate the impacts caused by city development and it can be enjoyed by all citizens of the city. The existence of a city park in Gianyar City is very important. The problems found in Gianyar city park is that the park lack of space function, especially the utilization of social and cultural space. The purpose of this research were to identify the physical, socio-cultural and historical condition of the three parks in Gianyar subdistrict and to plan the appropriate development concept of the site. This research was conducted from September 2016 to February 2017. The method used in this research were field survey method with observation, interview and distribution of questionnaire technique, and also by conducting literature study. Furthermore, data were processed by tabulation method and qualitative descriptive analysis method which refered to the stages of Simonds planning process (1983). The result of this planning was site plan image with the basic concept Tri Hita Karana (THK) concept at Dewa Wisnu Park, Mandara Giri park and Ciung Wanara of Park.

Keywords: Landscape developmen, landscape planning, Gianyar city park, Tirta amertha

\section{Pendahuluan}

Kabupaten Gianyar memiliki ruang terbuka hijau kota berupa taman kota yang berada di pusat kota Kabupaten Gianyar tepatnya di Desa Gianyar pada jalan Ngurah Rai sampai jalan Astina Timur, Kecamatan Gianyar yaitu Taman Patung Dewa Wisnu, Taman Mandara Giri dan Taman Ciung Wanara. Dari ketiga taman tersebut hanya satu taman yang sering dikunjungi dan menjadi titik pusat di kota Gianyar, yaitu taman kota Ciung Wanara Gianyar.

Jika dilihat dari segi sejarah, ketiga taman tersebut mempunyai kaitan dari urutan cerita yang diangkat pada masa pembangunan taman yang dihubungkan dengan cerita sosial dan budaya yang dimiliki oleh masyarakat Kabupaten Gianyar yaitu filosofi peristiwa 
perebutan Tirta Amertha yang di ambil dari cerita Itihasa Maha Bharatha yang pertama dalam kitab suci Adi Parwa buah karya "Bhagawan Abhiasa Kresna Dwipayana" (DKP dan Dinas PUPR Kabupaten Gianyar, 2016). Perencanaan taman kota di Kecamatan Gianyar, Kabupaten Gianyar, Provinsi Bali khususnya di jalan Ngurah Rai perlu dilakukan agar ketiga taman dapat digunakan dengan memaksimalkan fungsi berdasarkan dengan kesejarahan, sosial dan budaya sehingga menjadi satu kesatuan yang utuh sebagai taman Kota Gianyar.

Rumusan masalah penelitian ini antara lain 1) Bagaimana latar belakang sosial dan budaya yang menghubungkan ketiga taman tersebut? 2) Bagaimana konsep perencanaan taman yang sesuai dengan latar belakang, sosial dan budaya dari Kota Gianyar untuk ketiga taman tersebut sehingga menjadi satu kesatuan yang utuh?, dengan tujuan penelitian meliputi 1) Mengidentifikasi kondisi fisik, sosial, budaya dan kesejarahan dari ketiga Taman Kota Gianyar yang terletak disepanjang Jalan Ngurah Rai. 2) Membuat konsep perencanaan taman yang sesuai dengan latar belakang, sejarah, sosial, dan budaya ketiga taman. Oleh sebab itu dengan penelitian ini diharapkan dapat sebagai bahan pengembangan untuk merencanaan ruang terbuka hijau kota (RTHK) berupa taman kota di Kecamatan Gianyar sesuai kondisi sosial, kesejarahan, serta tata ruang.

\section{Metode Penelitian}

\subsection{Tempat dan Waktu Penelitian}

Penelitian ini dilakukan di sepanjang jalan Ngurah Rai sampai jalan Astina Timur Kecamatan Gianyar, Kabupaten Gianyar, Provinsi Bali. Penelitian ini dilakukan dari bulan September 2016 sampai Februari 2017.

\subsection{Alat dan Bahan}

Alat yang diperlukan dalam penelitian ini adalah alat tulis (pensil, kertas, bolpoin, komputer, dan lain sebagainya), kamera digital, perangkat lunak pengolah data, kata dan gambar (Microsoft word, Microsoft excel, Autocad2013, PhotoshopCS3, Paint). Bahan yang digunakan adalah lembar kuesioner dan lembar wawancara.

\subsection{Metode Penelitian}

Penelitian ini menggunakan metode survei lapangan dengan teknik observasi, penyebaran kuesioner, dan wawancara. Data yang telah didapat kemudian diolah menggunakan metode tabulasi dan analisis data selanjutnya disajikan dengan metode deskriptif.

\subsection{Tahapan Penelitian}

\subsubsection{Persiapan}

Persiapan berupa perijinan di lokasi penelitian dan pencarian umum tentang kondisi eksisting di lokasi penelitian, serta mempersiapkan alat yang diperluakan saat penelitian berlangsung.

\subsubsection{Inventarisasi}

Tahap awal dari studi ini adalah melakukan identifikasi dan inventarisasi data dilapangan dengan metode observasi, wawancara, serta penyebaran kuesioner. Tahap inventarisasi dilakukan dengan melihat kondisi lansekap taman yaitu dilihat dari aspek 
biofisik, aspek sosial dan aspek budaya. Aspek biofisik meliputi pola penggunaan lahan pada kawasan tapak pengamatan dan inventarisasi terhadap hardscape dan softscape taman. Sedangkan Aspek sosial meliputi prilaku masyarakat. Aspek budaya yaitu meliputi kesejarahan dari dibangunnya taman.

\subsubsection{Analisis}

Data diolah dengan metode analisis data dan tabulasi untuk diperoleh kelompok data potensi dan kendala yang terdapat pada tapak seperti data biofik, sosial budaya dan kesejarahan, kemudian data dijabarkan menggunakan metode deskriptif. Pengolahan data mengacu pada rumus perhitungan persentase Sudjana (2001). Bentuk persentase (\%) dengan perhitungan sebagai berikut::

$$
P=F / N \times 100 \%
$$

keterangan :

$\mathrm{P}=$ Persentase,

$\mathrm{F}=$ Frekuensi,

$\mathrm{N}=\Sigma$ total responden

\subsubsection{Sintesis}

Pada tahapan sintesis merupakan suatu tahap pemanfaatan potensi dan pemecahan masalah yang disesuaikan dengan tujuan penelitian. Berbagai potensi pada tapak diusahakan untuk dimanfaatkan dan dikembangkan. Hasil ini dikembangkan untuk mendapat konsep yang sesuai.

\subsubsection{Konsep}

Pada tahap ini merupakan pengembangan ide berdasarkan analisis yang didapatkan setelah melakukan kegiatan identifikasi. Konsep dibagi menjadi dua yaitu konsep dasar dan konsep pengembangan. Pada konsep pengembangan menggambarkan konsep ruang menjadi tiga bagian yaitu tata ruang tata sirkulasi dan tata hijau pada ketiga Taman Kota Gianyar.

\subsubsection{Perencanaan}

Tahap perencanaan akan menggambarkan tentang tapak pengembangan Taman Kota Gianyar yang mengacu dari konsep ruang menjadi tiga bagian yaitu tata ruang, tata sirkulasi dan tata hijau serta aktifitas, dan fasilitas. Setelah dilakukan analisis terhadap data hasil observasi, penyebaran kuesioner dan wawancara, selanjutnya akan lakukan tahap sintesis yaitu tahapan pemecahan masalah dari obyek penelitian.

\subsection{Batasan Penelitian}

Penelitian dibatasi pada perencanaan tiga taman di pusat kota Kabupaten Gianyar dilakukan sampai tahap sintesis dan perencanaan konsep pengempangan dengan membagi menjadi konsep tata ruang, konsep tata hijau, konsep sirkulasi dengan hasil akhir berupa peta rencana tapak (site plan). 


\section{Hasil dan Pembahasan}

\subsection{Kondisi Umum Pusat Kota kabupaten Gainyar}

\subsubsection{Biofisik}

Kabupaten Gianyar memiliki luas wilayah 368 km², terdiri dari tujuh kecamatan dikembangkan dalam lima zona dipetakan sesuai dengan potensi masing-masing wilayah dengan pusat kota berada di kecamatan Gianyar yang masuk dalam zona Gianyar Timur. Gianyar Timur (Kec. Gianyar) merupakan wilayah dengan zona daerah pusat pemerintahan dan fasilitas umum, pusat pendidikan, perdagangan dan jasa, warisan budaya dan wisata remaja, pertanian lahan basah, peternakan, dan industri pengolahan. Menjadi pusat kota kabupaten, Zona wilayah Gianyar Timur, Kecamatan Gianyar terletak antara 8026'23" - 8035'01" Lintang Selatan dan 115018'579" - 115022'23,7" Bujur Timur. Kecamatan Gianyar terdiri atas 5 Kelurahan dan 12 Desa. Pusat Kota Kabupaten Gianyar terletak di Kecamatan Gianyar tepatnya di Desa Gianyar yang dibagi menjadi banjar adat dan banjar dinas terdiri dari 10 banjar adat yaitu banjar Sampyang Gede, Sampyang Cenik, Sengguan Kawan, Sengguan Kangin, Teges Gede, Teges Cenik, Lekok, Sangging, Pasdalem, Candibaru dan tujuh banjar dinas di wilayah Kecamatan Gianyar, Kabupaten Gianyar, Bali (Bappeda Kab. Gianyar, Bps Kab. Gianyar, 2016).

\subsubsection{Sosial Budaya dan Sejarah}

Gianyar dipilih menjadi nama berangkat dari sebuah keraton Puri Agung yaitu Istana Raja (Anak Agung) bernama Ida Dewa Manggis Sakti. Sebuah kerajaan yang berdaulat dan otonom telah lahir serta ikut pentas dalam percaturan kekuasaan kerajaankerajaan di Bali. Sumber mata pencaharian masyarakat Gianyar di dominasi tidak jauh dari keadaan sosial dan budaya maupun potensi dari Kota Gianyar yang merupakan wilayah dalam zona Gianyar timur yaitu daerah pusat pemerintahan dan fasilitas umum, pusat pendidikan, perdagangan dan jasa, cultural heritage dan wisata remaja, pertanian lahan basah, peternakan, dan Industri pengolahan yaitu sebagai pegawai negeri sipil, pegawai swasta dan wirausaha (pelukis, pemahat, pematung, industri, dll).

\subsection{Identifikasi Tapak Taman di Pusat Kota Kabupaten Gianyar}

\subsubsection{Perkembangan Biofisik Taman}

Pembangunan ketiga taman yang berada di pusat kota Kabupaten Gianyar dibangun tahun 1994 (Wayan Winten, Agung Mayuni 2016) dibagun berdasarkan perintah Bupati Gianyar pada saat itu dengan mengangkat cerita perebutan Tirta Amertha sebagai konsep pembangunan taman. Letak ketiga taman masih tetap pada lokasi pertama di bangun dan terjadi sedikit perubahan pada tapak seperti perbaikan hardscape maupun softscape.

\subsubsection{Aspek Biofisik, Sosial Budaya dan Sejarah masing-masing Taman}

\section{Taman Patung Dewa Wisnu}

Taman yang dibangun pada tahun 1994 dengan luas 100m² (Wayan Winten, 2016). Berdasarkan hasil pengamatan langsung di lapang, tidak terdapat akses khusus masuk maupun keluar pada taman ini. Terdapat vegetasi eksisiting yang berada di dalam tapak serta adanya elemen keras (hardscape) seperti patung Dewa Wisnu membawa panah. Disekitar taman terdapat perkantoran, sekolah, serta terdapat banyak toko alat tulis 
dan percetakan disekitarnya. Pada bagian timur taman terdapat area suci yaitu sebuah Padmasana dan pura yang digunakan oleh masyarakat setempat dengan keadaan sangat terawat dan bersih. Taman ini biasanya digunakan sebagai tempat menyeberang oleh masyarakat, aktifitas lain juga terjadi di area taman seperti aktifitas persembahyangan yang dilakukan masyarakat sekitar taman pada area suci yang terletak di belakang taman Patung Dewa Wisnu. Kendala yang ditemukan saat pengamatan langsung di lapang yaitu tidak banyak aktivitas yang dapat dilakukan pada taman ini dikarenakan keadaan sekitar seperti arus lalu lintas yang cukup ramai, serta melihat dari keadaan yang tidak memungkinkan digunakan sebagai tempat bermain maupun berekreasi, minimnya fasilitas lalu lintas seperti tidak adanya tempat penyeberangan yang cukup memadai menjadi hal yang sangat membahayakan para pengguna taman, keadaan vegetasi juga kurang terawat serta tidak terdapat fasilitas taman seperti lampu taman maupun rambu-rambu pengunjung yang dapat menyebabkan terjadinya penyalah gunaan tempat umum.

\section{Taman Mandara Giri}

Dulunya taman ini merupakan taman dari bagian Puri Gianyar yang kemudian diambil alih oleh pemerintah Kota Gianyar dan sekarang difungsikan sebagai salah satu taman yang berada di Kota Gianyar dan berdampingan dengan pusat perbelanjaan (Agung Alit, 2016). Berdasarkan hasil pengamatan langsung di lapang, terdapat vegetasi eksisting yang berada di tapak serta terdapat elemen keras (hardscape) seperti adanya jalur paving bagi pejalan kaki dan penggunaan kolam air mancur Jatatunda dilengkapi dengan patung Dewa dan Ular Naga serta patung Kuda Uncir Srawa, terdapat juga bangunan suci yaitu Padmasana yang keadaannya sangat terawat dan bersih. Taman ini berdisi sejak tahun 1994 dengan luas $400 \mathrm{~m}^{2}$ (Wayan Winten, 2016). Kegiatan pada taman banyak dilakukan pada pagi hari sebagai tempat melintas masyarakat yang melakukan kegiatan pagi sekitar pukul 06.00 sampai 11.00 WITA. Kegiatan yang dilakukan seperti olahraga, kepasar, persembahyangan yang dilakukan oleh pegawai pusat perbelanjaan yang berada tepat disamping taman pada padmasana yang terdapat di bagian utara taman dan kegiatan lainnya yang bisa dilakukan masyarakat sekitar dengan berjalan kaki atau melewati bagian dalam taman. Pemanfaatan taman dilakukan juga saat hari-hari tertentu seperti saat hari raya keagamaan maupun hari nasional seperti pemanfaatan sebagian tapak taman sebagai tempat dibangunnya bangunan pos informasi, keamanan dan kesehatan yang tidak permanen.

Berdasarkan pengamatan langsung di lapang, kondisi taman saat ini terlihat minim pengunjung, Selain itu ditemukan kondisi fisik taman saat ini mengalami seperti kondisi area pejalan kaki sudah tidak memungkinkan untuk dilalui, beberapa vegetasi yang belum tertata dan mendapat perhatian dengan baik, banyaknya tanaman yang tumbuh melewati pagar pembatas taman, terdapat tanaman dalam pot yang penempatannya menghalangi beberapa area pejalan kaki, keadaan pohon-pohon peneduh yang sangat rimbun hingga daun dan ranting pohon mengarah ke area pejalan kaki, kondisi kebersihan yang tidak baik terlihat pada area kolam air mancur yang tidak berfungsi, air kolam keruh serta tidak terdapat pembatas yang cukup aman pada area kolam bawah dan terdapat banyak 
sampah yang tergenang didalam kolam, tidak terdapat lampu taman maupun ramburambu pengunjung yang dapat menyebabkan terjadinya penyalahgunaan tempat umum.

\section{Taman Ciung Wanara}

Berdasarkan hasil pengamatan langsung di lapang, terdapat vegetasi ekisting pada tapak dan elemen keras (hardscape) seperti penggunaan kolam air mancur yang mengelilingi patung raksasa Kalarau, patung Garuda Wisnu, Patung Kuda dengan Kereta, dan Patung Dewi Ratih. Pada taman ini terdapat bagunan suci Padmasana dan sebuah bangunan petugas keamanan. Taman ini berdisi sejak tahun 1994 dengan luas $500 \mathrm{~m}^{2}$ (Wayan Winten, 2016). Difungsikan sebagai taman kota aktif di Kota Gianyar dengan berbagai fasilitas dan utilitas yang disediakan bagi pengunjung taman. Pengunjung taman merupakan dari semua kalangan usia dan sebagian besar mengunjungi taman bersama keluarga maupun rekan dengan kegiatan yang dilakukan beragam seperti sekedar bersantai menghilakan jenuh dan berolahraga. Adanya beberapa kendala pada taman ini seperti keadaan tanaman yang tidak terawat, kurangnya tanaman peneduh pada taman dan penempatan fasilitas bangku taman yang kurang sesuai menjadi sorotan masyarakat maupun pengunjung, jarak bangku taman yang sangat dekat dengan kolam air mancur, kurangnya fasilitas parkir pengunjung saat pagi dan siang hari pada taman ini.

Dari kendala dan potensi yang didapatkan pada masing-masing tapak maka rencana tata vegetasi dan sarana akan disesuaikan dengan aktifitas yang berlangsung (Raflis, 2008). Penataan vegetasi dioptimalkan dengan cara ditata sesuai dengan fungsinya sebagai peneduh, pengarah, pemberi estetika, maupun border, sedangkan vegetasi yang mengganggu (tumbuhan liar) dibersihkan (Firmansyah, 2010). Pada Taman Mandara Giri dan Taman Ciung wanara rencana penambahan fasilitas disesuaikan dengan aktifitas pengguna sebagai taman rekreasi penambahan fasilitas tapak sebagai tempat persinggahan untuk menyeberang dengan penambahan fasilitas penyeberangan seperti zebra) dengan lampu kedip pada Taman Patung Dewa wisnu. Rencana tata ruang dan tata sirkulasi dipilih untuk membantu menyelesaikan masalah pada tapak dengan membagi tapak menjadi beberapa ruang yang sesuai dengan keadaan sosial dan budaya pada tapak dan kebutuhan ruang aktifitas para pengguna tapak (Francis dan Ching, 2000).

\subsubsection{Aspek Kesejarahan Taman}

\subsubsection{Filosofi Sejarah Taman Kota Gianyar}

Pembangunan tiga taman yang terdapat di Kota Gianyar dibangun dengan mengangkat filosofi dari cerita perebutan Tirta Amertha (perebutan air kehidupan). Cerita perebuatn Tirta Amertha berawal dari keinginan pada dewa untuk mendapatkan Tirta Amertha (air kehidupan), maka Dewata Nawa Sanga bekerjasama dengan para Raksasa untuk mendapatkan tirta yang dimaksud, Tirta Amertha akan didapat dengan cara memutar atau mengaduk kolam susu, maka di pindahkanlah gunung Mandara Giri ke dalam kolam susu, setelah gunung Mandara Giri berada dalam kolam susu, maka dimintalah bantuan Ular Besar (Naga) untuk membelit gunung tersebut, akan tetapi kecurangan terjadi karena ulah para Raksasa yang telah diketahui oleh Dewa Surya, Dewi Ratih dan Dewa Wisnu. Maka terjadilah perebutan Tirta Amerta oleh Dewata Nawa Sanga 
dan Raksasa yang kemudian dimenangkan oleh Dewa Surya, Dewi Ratih dan Dewa Wisnu.

\subsubsection{Pengaruh Filosofi, Perkembangan Fisik dan Kondisi Sosial Budaya Kota Gianyar}

Dikaitkan dengan cerita sejarah, jiwa kesenian yang dimiliki ke tujuh kecamatan di Gianyar di filosofikan sebagai Tirta Amertha yang artinya air suci kehidupan yang diperebutkan dan dipertahankan oleh masyarakat Gianyar. Kemudian diaplikasikan kedalam pembangunan taman dengan menggunakan elemen hardscape yaitu adanya pancuran kolam Jalatunda sebagai bentukan hardscape dari Tirta Amertha (air suci kehidupan) yang mengalir ke segala arah yang diartikan berkelanjutannya jiwa kesenian Gianyar dalam bidang sosial, politik, perekonomian, budaya daerah, pekerjaan masingmasing kecamatan tetap berjalan dan memberi keberlangsungan kehidupan yang baik bagi masyarakat dan Kabupaten Gianyar.

\subsection{Konsep Dasar dan Pengembangan}

Konsep dasar dari Perencanaan Lansekap taman kota di Kecamatan Gianyar, Kabupaten Gianyar, Provinsi Bali adalah peningkatan kualitas tapak taman agar ketiga taman menjadi satu kesatuan utuh sesuai filosofi yang diangkat mengandung hikmah keseimbangan dan keadilan, serta mengatasi berbagai permasalahan yang ada pada tapak dan berfungsi dengan baik sesuai keadaan lingkungan sosial budaya sekitar. Dengan konsep pengembangan yaitu menggunakan konsep Tri Hita Karana atau Tiga Penyebab Kesejahteraan (THK) sehingga terwujudnya keseimbangan, kesetaraan dan keadilan. Dengan rencana pengembangan seperti tata ruang, tata hijau dan tata sirkulasi.

\subsubsection{Tata Ruang}

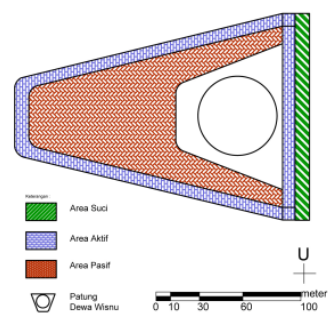

A.Taman Patung Dewa Wisnu

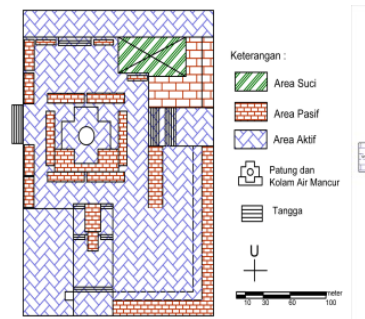

B.Taman Mandara Giri

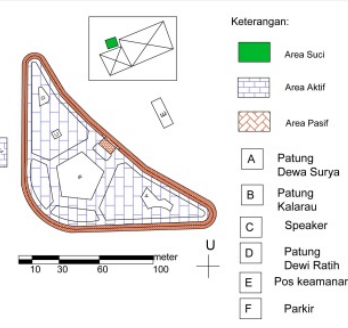

C. Taman Ciung Wanara

Gambar 1. Block plan Tata Ruang Taman

Rencana tata ruang dibagi menjadi tiga area yaitu area suci, area aktif dan area pasif (Gambar 1A-1C) mengikuti konsep pengembangan dari konsep dasar Perencanaan Lansekap taman kota di Kecamatan Gianyar, Kabupaten Gianyar, Provinsi Bali, sehingga perencanaan lansekap taman mengunakan konsep pengembangan yaitu Tri Hita Karana atau Tiga Penyebab Kesejahteraan (THK) sehingga terwujudnya keseimbangan, kesetaraan dan keadilan. Pada ketiga tapak area suci (hubungan manusia dengan tuhan) yang berfungsi sebagai tempat persembahyangan bagi para pengguna yang dominan beragama Hindu. Area aktif (hubungan manusia dengan manusia) dan area pasif (hubungan manusia dengan lingkungan) berfungsi sebagai tempat berjalannya aktifitas antar pengguna pada tapak (Mahatvayudha, 2012). 


\subsubsection{Tata Hijau}

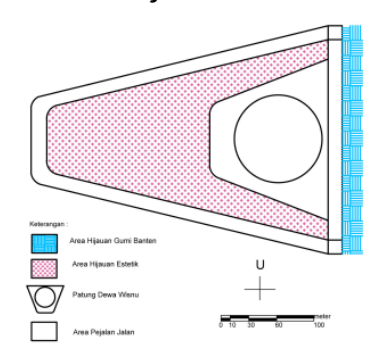

A.Taman Patung Dewa Wisnu

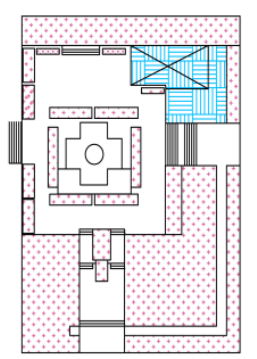

B.Taman Mandara Giri

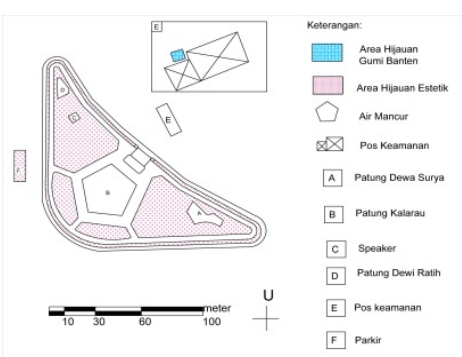

C. Taman Ciung Wanara

Gambar 2. Block plan Tata Hijau Taman

Rencana tata hijau direncanakan dengan melihat dari kondisi biofisik dan rencana tata ruang dan menggunakan konsep Asta Dala (perputaran alam dengan delapan penjuru mata angin). Dibagi menjadi dua area hijauan yaitu area hijauan estetik yang terletak pada area aktif serta pasif, dan area hijauan Gumi Banten (Gambar 2A-2C) terletak pada area suci. Area suci terdapat konsep taman Gumi Banten yang memperkuat ciri khas budaya Bali dengan klasifikasi tanamannya yang dapat tumbuh dengan baik diarea tapak yang ditempatkan di area suci sehingga dapat berfungsi sebagai penanda area suci maupun sebagai penunjang sarana persembahyangan. Sedangkan pada area aktif dan pasif dengan konsep tata hijau taman estetik untuk memperindah taman dan tempat parkir dengan penggunaan tanaman-tanaman lokal yang dapat tumbuh dan sudah beradaptasi dengan baik. Selain itu memperhatikan perawatan serta pengelolaan vegetasi, klasifikasi dan penempatan tanaman disesuaikan dengan fungsinya seperti sebagai peneduh, pengarah, border, estetik maupun sebagai sarana persembahyangan

\subsubsection{Tata Sirkulasi}

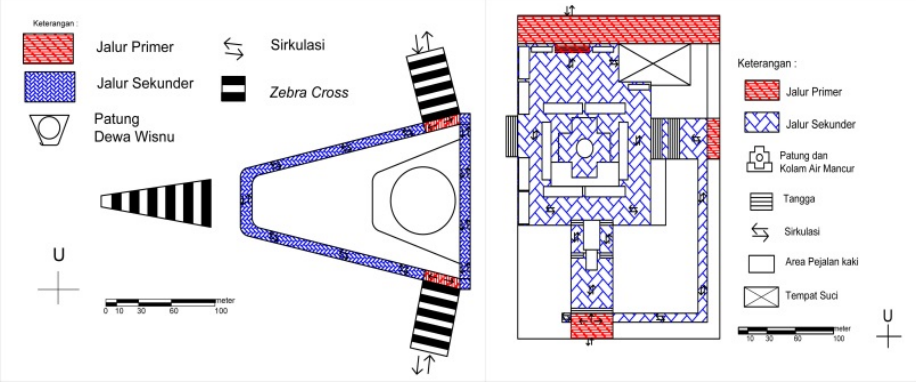

A.Taman Patung Dewa Wisnu

B.Taman Mandara Giri

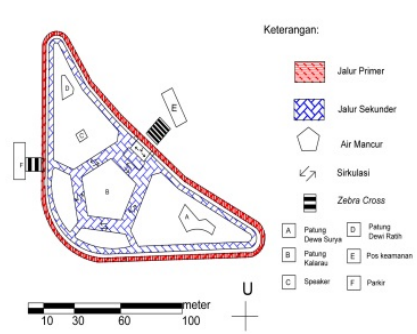

C. Taman Ciung Wanara

Gambar 3. Block plan Tata Sirkulasi Taman

Pada ketiga tapak taman menggunakan konsep sirkulasi yang direncanakan sesuai jalur-jalur yang menghubungkan antara satu ruang dengan ruang lainnya dan pengembangan sirkulasi dilakukan berdasarkan kondisi fisik, kebutuhan tapak dan ruang yang ada sehingga konsep sirkulasi membagi jalur sesuai kegunaan (Simonds, 2006). Sirkulasi pada tapak dibagi menjadi jalur primer dan sekunder (Gambar 3A-3C), yaitu: 
Jalur primer merupakan sirkulasi yang menghubungkan antara ruang parkir dan jalan utama menuju taman. Jalur ini dibuat 2 arah untuk memudahkan akses keluar masuk pengguna dari parkir menuju area taman. Jalur sekunder merupakan sirkulasi jalur manusia yang memudahkan menghubungkan antar ruang didalam area taman dan hanya dapat diakses oleh pengunjung pejalan kaki.

\subsubsection{Hubungan Antar Ruang, aktivitas dan fasilitas}

Ruang-ruang yang direncanakan saling terhubung pada masing-masing tapak melalui aktivitas maupun fasilitas yang direncanakan. Pada lansekap masing-masing tapak hubungan antar ruang, aktivitas dan fasilitas akan memudahkan pengguna dalam mengakses area yang ingin dijangkau sesuai fungsi serta kegunaan masing-masing tapak. Hubungan antar ruang yaitu ruang suci, aktif dan pasif dengan aktifitas pengguna terjadi hubungan yang saling terkait, tidak terkait, maupun terkait secara tidak langsung yang dapat mempengaruhi kebutuhan akan fasilitas pada taman.

\subsubsection{Hubungan Antar Taman}

Hubungan antar taman saling terkait hardscape dari masing-masing taman yang merupakan sebuah satu kesatuan cerita atau kisah dari perebutan Tirta Amertha yang diangkat sebagai filosofi terbangunnya tiga taman ini serta disepanjang jalan yang menghubungkan ketiga taman terdapat tanaman glodokan tiang. Ketiga taman tersebut berada di tengah kota dengan satu jalan yang sama yaitu di jalan Ngurah Rai sampai jalan Astina Timur. Dengan jalur yang di rencanakan dalam kota seperti pada taman yang pertama dikunjungi adalah Taman Mandara Giri kemudian menuju Taman Patung Dewa Wisnu dan yang terakhir yaitu Taman Ciung Wanara.

\subsection{Perencanaan}

Konsep tata ruang, tata hijau dan sirkulasi yang telah dijabarkan, selanjutnya akan digambarkan dalam bentuk site plan yang dapat dilihat pada gambar 24-26 yang merupakan produk penerjemah konsep perencanaan dalam bentuk gambar, serta merupakan pendetailan dari block plan. Melalui tampak atas pada site plan sudah dapat dilihat bentukan objek, ruang, dan beberapa elemen yang tersedia (Premana, 2012). 


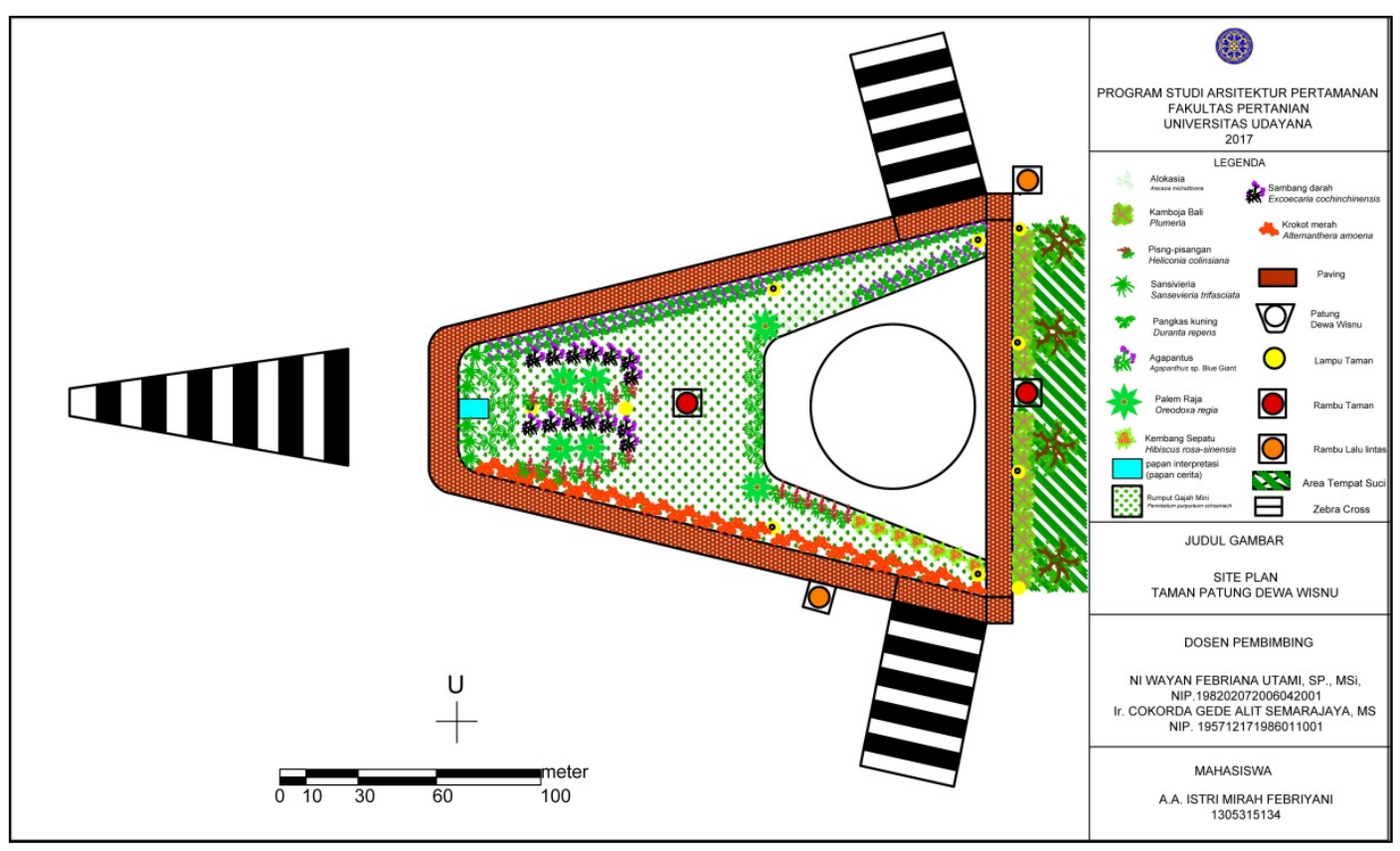

A. Taman Patung dewa Wisnu

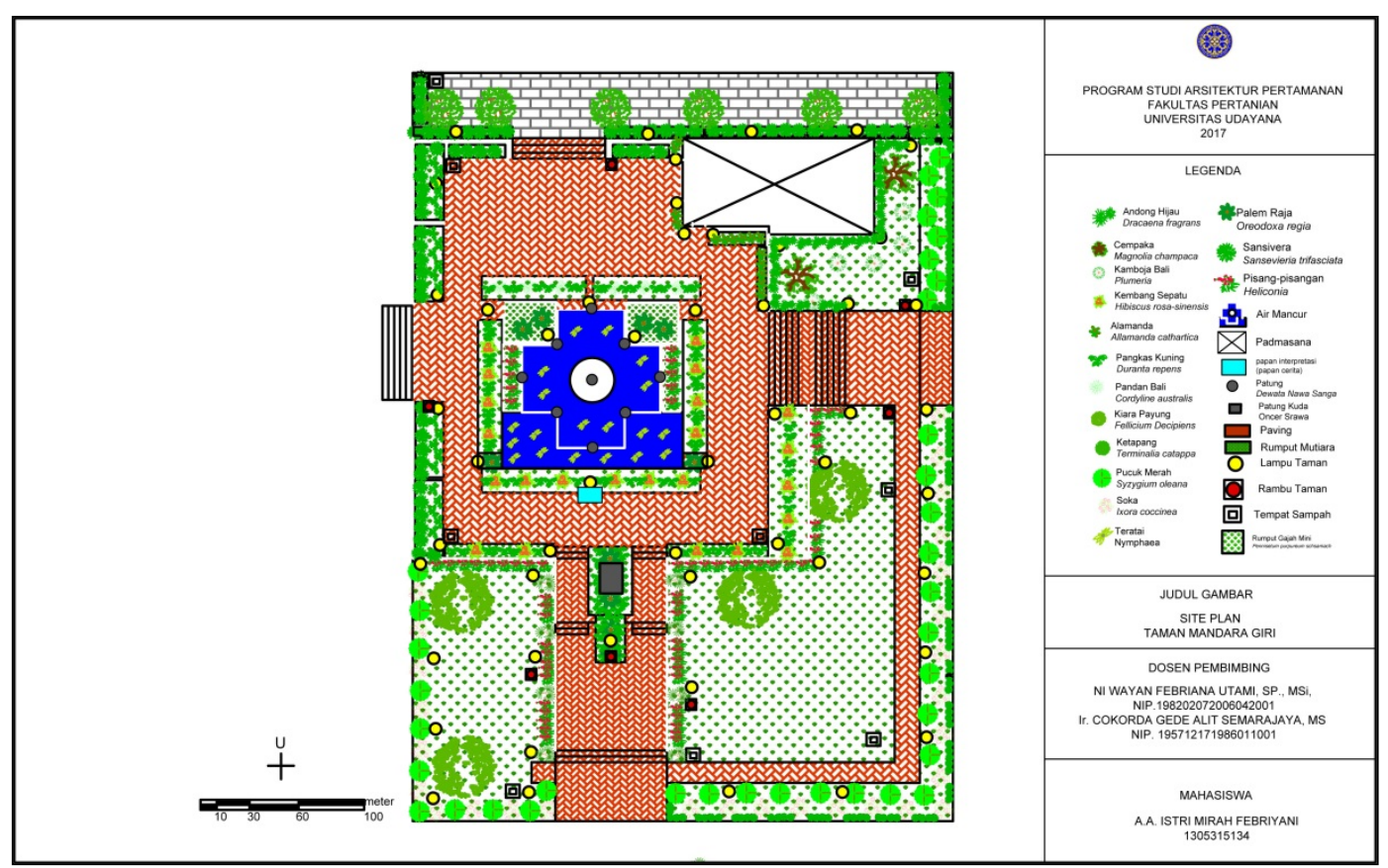

B. Taman mandara Giri 


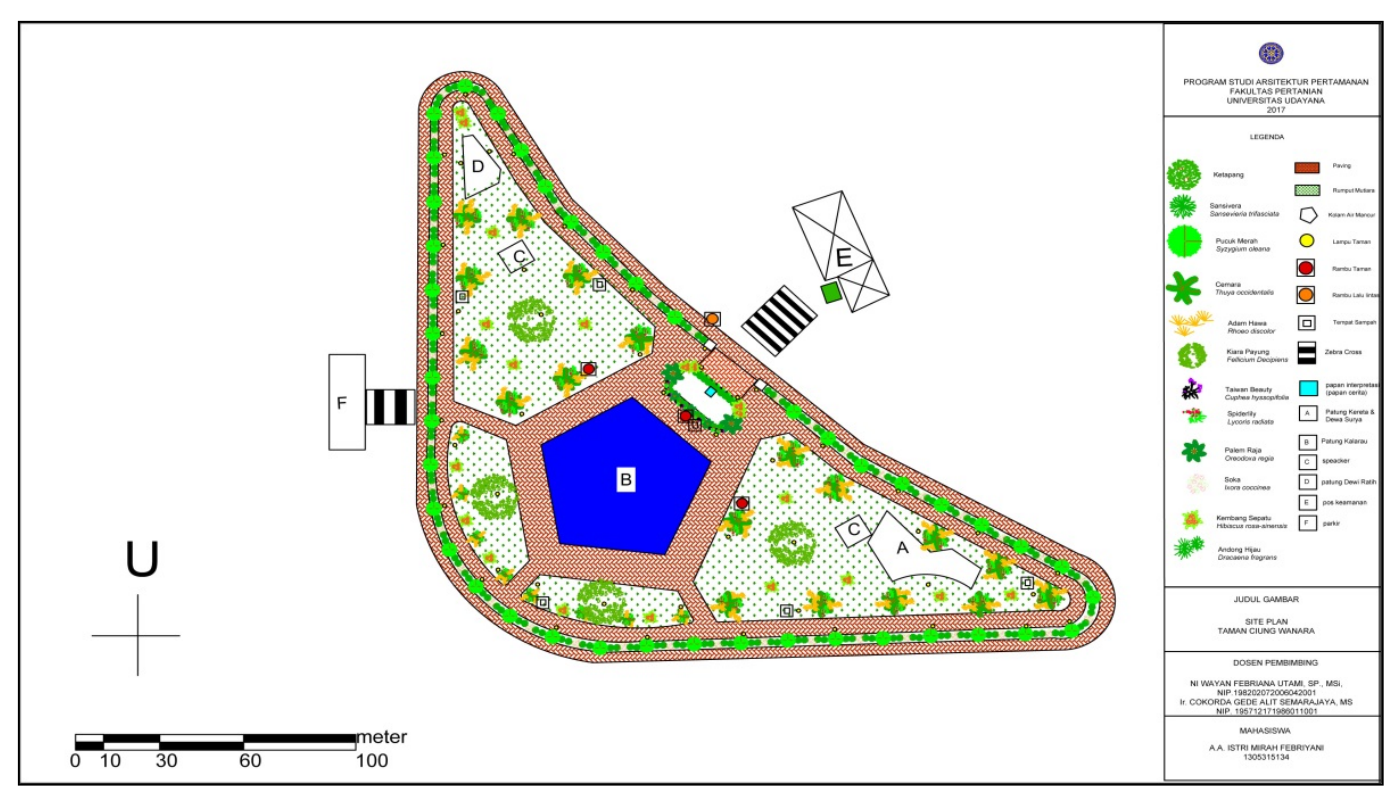

C. Taman Ciung Wanara

Gambar 3. Siteplan Taman

\section{Simpulan dan Saran}

\subsection{Simpulan}

Ketiga taman yang berada di pusat kota Kabupaten Gianyar saling berkaitan melalui latar belakang sosial dan budaya yang juga terlihat dalam persebaran karakteristik fisik hardscape dari filosofi sejarah yang digunakan pada masing-masing taman yaitu peristiwa perebutan Tirta Amertha, kemudian dikembangkan melalui perencanaan lansekap taman Kota Gianyar dengan tetap mengacu pada konsep awal pembangunan taman sebagai ruang terbuka hijau kota berupa taman kota. Konsep dasar taman dikembangkan dari Konsep Tri Hita Karana atau Tiga Penyebab Kesejahteraan (THK) dimana konsep tersebut sangat sesuai karena mencerminkan keseimbangan dan keadilan melalui hubungan baik dengan lingkungan, dengan sesama, dan hubungan dengan Tuhan Yang Maha Esa serta terciptanya fungsi sosial dan budaya pada masing-masing taman sesuai aktivitas pengguna taman seperti sebagai taman lalu lintas maupun taman kota sebagai tempat berekreasi. Pengembangan konsep tersebut kemudian dituangkan ke dalam konsep rencana tata ruang, tata hijau dan tata sirkulasi. Yang selanjutnya tertuang dalam gambar site plan.

\subsection{Saran}

Hasil Penelitian Perencanaan Lanskap Taman Kota Gianyar, Kabupaten Gianyar, Provinsi Bali ini diharapkan dapat menjadi bahan pengembangan untuk perbaikan perencanaan Taman Kota Gianyar yang sesuai dengan fungsi tapak sebagai ruang terbuka hijau kota serta sesuai dengan keadaan lingkungan sosial dan budaya sekitar.

\section{Daftar Pustaka}

Bappeda Gianyar. 2015. Profil Daerah kabupaten Gianyar Tahun 2015. [Online]. Tersedia di: http://bappeda.gianyarkab.go.id/index.php/page/4/Profil-DaerahKabupaten-Gianyar-Tahun-2015.html [Diakses 06 Februari 2016]. 
BPS Kabupaten Gianyar. 2015. Kecamatan Gianyar dalam angka Tahun 2016. Badan Pusat statistik Kabupaten Gianyar, Bali. [Online]. Tersedia di: https://gianyarkab.BPS.go.id/2015/website/pdf_publikasi/Kecamatan Gianyar-Dalam-Angka-2016.pdf. [Diakses 06 Februari 2016].

Dinas Kebersihan dan Perkebunan. 2016. Filosofi pembanguna Taman Kota Gianyar.

Fahlevi. 2013. Perancangan Ulang Kawasan Pemakaman Umum Tanah Kusir, Jakarta Sebagai Salah Satu Bentuk Pemanfaatan Ruang Terbuka Hijau Ramah Burung. Institut Pertanian Bogor. [Online]. Tersedia di : http://repository.ipb.ac.id/handle/123456789/61210. [diakses 17 Juni 2017].

Humboli (2000). Pengertian Lansekap secara Umum. [Online]. Tersedia di: http://www.galeripustaka.com/2013/03/pengertian-lanskap-secara-umum.html. [Diakses 03 Juli 2016].

Laurie (1986). Perencanaan Lansekap dan Prosesnya. [Online]. Tersedia di: https://artikelbermutu.com/2014/04/perencanaan-lanskap-dan-prosesnya.html\#. [Diakses 03 Juli 2016].

Mahatvayudha, P.G.B. 2012. Perencanaan Lansekap Kampus Fakultas Pertanian Universitas Udayana Jimbaran, Bali. Skripsi Universitas Udayana (tidak dipublikasikan).

Nurisyah, S dan Q. Pramukanto. 2001. Perencanaan Kawasan untuk Pelestarian Lansap dan Taman Sejarah. Bogor: Institut Pertanian Bogor.

Pradika, Angga. 2013. Strategi Pengembangan Objek Wisata Waduj Gunungrowo Indah dalam Upaya meningkatkan Pendapatan Asli daerah (PAD) Kabupaten Pati. Skripsi. Universitas Negri Semarang.

Raflis (2008). Lansekap, Sustainable Development dan MDGs. [Online]. Tersedia di: http://rencanatataruangriau.blogspot.com/2008/08/lansekap- sustainabledevelopment-dan.html . [Diakses 22 Februari 2017].

Simonds, J. O. 1983. Landscape Architecture: A Manual Site Planning and Design. McGraw-Hill Book Co. Inc, New York.

Troll (1970). Pengertian Lansekap Secara Umum. [Online]. Tersedia di: http://www.galeripustaka.com/2013/03/pengertian-lanskap-secara-umum.html. [Diakses 03 Juli 2016].

Undang-undang RI Nomor 26. 2007. Penataan Ruang. [Online]. Tersedia di: http://conflictresolutionunit.id/uploads/resources/UNDANG-UNDANGNOMOR-26-TAHUN-2007.pdf.

Widodo, A. (2013). Perencanaan Tata Hijau Simpang Susun Dawuan Jalan Tol Cikampek. Institut Pertanian Bogor. [Online]. Tersedia di: http://repository.ipb.ac.id/bitstream/handle/123456789/64979/A13awi.pdf ?sequence=1\&isAllowed=y [Diakses 26 Juli 2017]. 